\title{
Resilience in African American Single-Parent Households: Perceptions of Predictors for Academic Success
}

\author{
Jackson de Carvalho, PhD \\ Associate Professor \\ Prairie View A \& M University \\ Prairie View, Texas 77446 \\ United States of America \\ Beverly Spears, PhD \\ Assistant Professor \\ Brailsford College of Arts and Sciences \\ Prairie View A\&M University \\ Prairie View, Texas \\ United States of America
}

\begin{abstract}
The notable increase in academic success among youth from a single parent, African American families, has occurred in the shadow of years of oppression, historical trauma, and differential treatment related to race, gender and income. Research on resilience has consistently shown that low levels of income and single parenting are two potent risk factors that tend to have adverse impacts on families and children. This study focus on the manifestation of resilience in children who live in homes that are headed by African American mothers. The purpose of this study is to delineate the factors that influence resilience and academic achievement of African American youth that live in African American, female-headed, single parent, households. This study contributes to the existing body of knowledge by increasing understanding regarding the life experiences of female single parents and their children. Subsequently, educators, school administrators, and policymakers can be better informed to assist children of single parents in having the opportunity to succeed academically and become contributing members of society. Additionally, understanding how certain individuals overcome adversity and challenges will lead to the development of successful interventions, policies, and practices for others facing similar challenges. Each year thousands of students leave school without graduating, and this problem is exacerbated in the African American community.
\end{abstract}

Keywords: African American females, teachers, academic success, post-secondary institutions.

\section{Introduction}

The notable increase in academic success among African American students that come from African American, femaleheaded, single parent, households has occurred in the shadow of years of oppression, historical trauma, and differential treatment related to race, gender and income. The plight of youth living with single mothers on low-income,struggling to overcome barriers while striving to succeed is a critical issue facing the current social context (Archer-Banks, \& Behar-Horenstein, 2012). Research on resilience has consistently shown that low levels of income and single parenting are two potent risk factors that tend to have adverse impacts on families and children (Bryant, \& Center for Law and Social Policy, 2015). Several million American children younger than 18 live in female-headed low-income single parent homes below the poverty line, and more than one out of every six American children (17.8 percent) are considered poor. Youth living in female-headed, single parent, households in 2018, were much more likely to be poor than those living in dual-parent households (Child Trends Databank, 2019; Fox, 2018).

Some of the statistics associated with single parenting and poverty as reported by Chaudry and Wimer (2016) are: every 36 seconds a child is born into poverty; 12.9 million children are poor, and 5.6 million of them live in extreme poverty and are unable to provide basic necessities such as food and shelter. Cokley, McClain, Jones, \& Johnson (2011) suggested that children who live with high levels of social and demographic risks are more likely than other children to experience higher levels of behavioral and emotional problems. Children from high-risk families are also more likely than other children to have been suspended or expelled from school or to have skipped school, and they are disproportionately more likely to be poorly engaged in school (Edelman, 2016). 
This study focuses on the manifestation of resilience in children who live in homes that are headed by African American females on low-income. The purpose of this study is to delineate the factors that influence resilience and academic achievement among African American youth that live in African American, female-headed, single parent, households. This study contributes to the existing body of knowledge by increasing understanding regarding the life experiences of female single parents and their children. Subsequently, educators, school administrators, and policymakers can be better informed to assist children of single parents in having the opportunity to succeed in life and become productive members of society (Archer-Banks, \& Behar-Horenstein, 2012; Arrington, \& Wilson, 2000).

Many single-parent families are caught up in the change and complications of the new millennium and often find that they are ill-equipped to handle the stresses placed on them (deCarvalho, \&Colvin, 2015). Fortunately, even with adversities such as single-parenting, poverty, and an at-risk childhood, some individuals who demonstrate resilient behavior can rise above risk, and the challenges of their environments to succeed in life (deCarvalho, \&Colvin, 2015; Lipsky, \& Johnson, 2010).

\subsection{Review of Literature}

The literature review will provide support and clarity to the study by revealing concepts that address historical, societal, individual and single-parent family-related factors that impact academic success in children raised by African American, female, single parents. Cunningham, Corprew, and Becker (2009) suggested that the latter part of the 20th century and the first part of the 21 st century could be characterized as the era of family transformation and stress. The family form is more diverse and more populated by single-parent households, blended family units, interracial marriages, and what demographers refer to as the new "stepfamily systems", which are created by cohabitation (ArcherBanks, \& Behar-Horenstein, 2012).

The seminal works of Mistry, Vandewater, Huston, and McLoyd (2002) provided both longitudinal and cross-sectional studies that emphasized the impact that family environments have on the youth. Mistry et al., (2002) suggested that a correlation exists between family protective factors that promote resilience and the child's developmental outcome. Other researchers such as Hetherington \& Stanley-Hagan (2002) studied both single- and dual-parent households and determined that the outcomes of children from structured dual-parent families fared far better than did single-parent families. A longitudinal research study conducted by the National Center for Education Statistics (2016) found that a nurturing and stable home environment was a significant protective factor that mitigated risks for children and adolescents living in low-income and single-parent environments.

Allen (2015) suggested that the construct of family stability or resiliency should not be viewed as a fixed attribute, but as factors that can be changed to minimize adverse impacts on positive outcomes. Giacobbe, Traynelis-Yurek, and Lauren (1999) stated: "the theory of resiliency emphasizes possibilities rather than problems, options rather than constraints, and wellness rather than sickness" (p.1). According to Morris, (2016), this approach does not promote attributes such as ability, since such attribute is not a predictor of resilience among students.

\subsection{Problem Definition}

Researchers have suggested that much needs be done in the area of childhood interventions, in an attempt to improve family and child health, educational attainment, and economic well being, especially among diverse populations (Allen, 2015). Moreover, the societal problems of single parents overloaded with personal and financial hardships need to be addressed. These factors place the children and their families at extremely high risk for anxiety, depression, and other health problems (deCarvalho \& Colvin, 2015; Fox, 2018).

According to Smith-Evans and George (2014), the increasing participation of single mothers in the labor force, the changing nature of the family structure, and the composition of communities and households all create challenges to family and individual protective factors. Cokley, et al. (2011) presented the idea that environmental protective mechanisms, such as family unity and happiness, the lack of internal stress, and the availability of external support systems that encouraged and reinforced children's coping efforts, serve as potential protective mechanisms that are important to the development of self-esteem and resilience. Unfortunately, these factors are often lacking in many single parent homes. Researchers and policymakers often overlook the risks and challenges faced by youth living in female-headed, single parent households. There is a lacuna in the resilience research literature that examine factors responsible for the academic success of African American students from low-income single-parent families. Educators are often challenged to create alternative academic solutions for students who are not successful in their assignments and exams. This issue has generated significant concerns for educators and policymakers at the state and national level due to GPA disparities between African American students and their Caucasian counterparts. Failure to obtain a high school diploma, for African American youth, significantly increases the likelihood of unemployment, low-wage work, and incarceration (Crenshaw, 2012; Stinson, 2011). 


\subsection{Historical Factors and Resilience among African Americans}

The relevance of the historical portion of the literature review is to develop an understanding of the fact that in years past, members of the African American community were resilient and rose above adversity despite distressing circumstances; yet today many African American families and youth are failing to achieve success. The brevity of the historical portion is based on a lack of literature that links resilience and African American history. There was a time when African Americans had a greater appreciation for opportunities for education and success, so much that they died for it (Edelman \& Jones, 2004; Hoffer, 2014). Moreover, Washington (1901) argued that people who were not there in the early twentieth century could not understand the desire that the African Americans showed for education as a way to lift themselves from oppression.

Few can argue that African Americans face challenges that are socially, politically, and culturally different from any other race in the history of America. The literature review showed that past research failed to acknowledge or give credence to historical factors that may have contributed to African Americans issues. Harry, Klingner \& Hart (2005), posited that the literature on minority families is often manipulated to serve the needs and interests of dominant groups. It is beyond the scope of this study to provide a detailed account of African American history, however, Price (2015) noted that public constructions of the African American family structure and practice have historically been colored by an overwhelming assumption of deficit, making it difficult to separate the real effects of poverty and historical, discrimination from the continuation of negative stereotypes.

A plausible explanation for some of the self-defeating behaviors of African Americans is found in the seminal research of Price (2015) where she implies that individual and family outcomes generally worsen as the number of risks increase, and concomitantly, resilience fails to take place. In other words, the traumatic experiences of being constantly bombarded with a plethora of risk factors and barriers to resilience serve as unique obstacles facing African Americans.

\subsection{Risk Factors}

According to Lipsky \& Johnson (2010), the concept of risk factors has been described in the resilience literature as conditions that increase one's vulnerability to, or likelihood of experiencing undesirable or adverse events that may compromise health, psychological well-being, social performance, or resilience. Arrington and Wilson (2000) investigated the relationship between the number of risk factors to which African American families were exposed and the probability that they were experiencing academic or behavioral problems. O'Malley (2015) conducted a similar study, which examined the relationship between child stressors and family risk factors, and the behavioral adjustment of African American youth. These studies concluded that there is a positive relationship between the number and frequency of stress and risk factors, and the extent of academic, psychological and behavioral problems in observed children. These findings and similar research provide a clear understanding that disproportionately, African American families are at risk. Their environment is often one that contributes to the development of additional factors that hamper resilience (Gilliam, Maupin, \& Reyes, 2011; Lacour \& Tissington, 2011).

Other correlating risk factors leading to academic or behavioral problems include high rates of unemployment, crime, substance abuse, exposure to and involvement in violence; psychological distress; broken families and other debilitating effects of socioeconomic disadvantage. There are volumes of documented research indicating that growing up in a poor single-mother family contributes to adverse child development and negative life outcomes ( $\mathrm{O}^{\prime} \mathrm{Malley}$, 2015). There is a strong association between poverty and poor cognitive, social, and academic outcomes for children. Poor children are at higher risk for behavioral problems, depression, peer conflict, and low self-confidence (Lipsky \& Johnson, 2010; Snyder, \& Dillow, 2015).

Children living in poverty exposed to multiple risks (e.g., single-parenting, minority status, health problems, chronic poverty, and very-low-income neighborhoods), are more likely to have lower IQs than their middle-class counterparts and are slower in developing language and literacy skills (Lacour \& Tissington, 2011). Critics of those suppositions argue that those who perpetuate images of the stereotypical low-income single mother of color perpetuate dangerous myths about single motherhood in that they cause observers to make superficial judgments about the outcome of the mother and the minor children.

\subsection{Protective Factors}

On the other hand, the research findings of Brody(2002), Chaudry and Wimer (2016) and Swain (2006) validated the vital contribution of protective factors in the occurrence of resilience or positive outcomes in African American families by including data from both parents and children; and direct observations in their study of risk and protective factors in rural, single mother-headed, African American families. 
Brody (2002) found that protective domains, especially parenting protective factors (i.e., parental satisfaction, optimism), facilitated greater self-regulation than did community or child protective or risk factors. Maternal risk (i.e., unemployment, less than 12 years of education, giving birth before age 17) had the most significant adverse effect on child self-worth. Results also revealed that protective factors moderate the relationship between risk factors and child outcomes (Brody, 2002).

The research studies of Allen (2015) and Archer-Banks and Behar-Horenstein (2012) indicated that protective factors addressed in resilience studies are generally found within the individual and include a sense of being loved, possession of effective coping skills, sense of control, high self-esteem and self-efficacy, possession of specific personal characteristics, positive ethnic identity, and sense of spirituality. Although there is no consensus on how resilience is operationalized, many researchers examine two critical concepts that are intrinsically present in the understanding of resilience: risk factors and protective factors.

Risk and protective factors can be categorized as most closely associated with one of three domains: individual, family, and environment (O'Malley, 2015). Although risk factors refer to conditions that increase the likelihood of developing a problem, protective factors imply conditions that buffer, interrupt, or prevent problems from occurring (Crenshaw, 2012). An accentuated focus on protective factors and vulnerability has significantly contributed to the understanding of how people negotiate and cope with risks in the face of adverse circumstances (Price (2015).

\subsection{Factors that influence resilience and academic achievement}

Some of the risk factors intrinsically based within the individual include age, and the presence or absence of physical and mental health problems, behavior problems, learning disabilities, and substance abuse. Manago, Brown and Leaper (2009) and Price (2015) indicated that protective factors addressed in resilience studies are generally found within the individual and include a sense of being loved, possession of effective coping skills, sense of control, high self-esteem and self-efficacy, possession of specific personal characteristics, positive ethnic identity, and sense of spirituality.

Given the conceptual complexities of resilience, it is essential to view the individual factors holistically from birth through adulthood, family dynamics, and environmental predictors, which resilience either develops or fails to materialize. By focusing on risks and protective factors and their influences on the individual, those interested in resilience can better design effective interventions designed to improve the levels of functioning for individuals and families (Crenshaw, 2012; Gershenson, Holt, \& Papageorge, 2016).

According to Price (2015) and Crenshaw (2012), there are many factors responsible for at-risk students to become resilient and academically successful despite adversity. The evidence of such factors in the research literature confirm the suspicion that resilient individuals cope with life stressors and traumatic experiences differently. A central theme connecting all of the factors responsible for at-risk student becoming resilient is the emphasis on both individual characteristics and environmental factors.

\subsection{Individual Characteristics}

Researchers have identified many critical individual characteristics that promote resilience in children. Several studies have echoed the finding that children with high intelligence have a greater capacity to withstand extreme environmental stress than those who are less gifted (deCarvalho \& Colvin, 2015; Richman \& Fraser, 2001). The studies of Harry, et al. (2005); Price (2015) and Smith-Evans and George (2014)found that characteristics such as being easygoing and having an optimistic outlook with hopes and dreams for the future have also been found to buffer children from adversity. The sense of belonging to an ethnic group and identification with a particular culture seems to help children in countering and overcoming difficult situations in life; and also appear to build self-esteem and self-efficacy. Positive racial identity has also been found to protect African American adolescents against the presence of adversity in urban environments (Cokley, McClain, Jones \& Johnson, 2011; Manago, Brown, \& Leaper, 2009).

According to Palmer, Davis, and Hilton (2009), in order for resilience interventions and programs to succeed, the individual must have self-esteem and self-efficacy. They posited that children who can control their impulses are in a position to overcome neighborhood risk by being able to benefit from instruction, stay on task, pay attention in school, and, thereby, learn more than children who cannot do so.

Research has found that strict parenting that provides clear boundaries and expectations, combined with supervision and high levels of warmth distinguishes resilient, academically successful and high achieving poor inner-city children from their non-resilient, low-achieving peers (Hetherington, \& Stanley-Hagan, 2002; Price, 2015). It follows that parenting that is punitive and lacks warmth will be associated with lower levels of achievement and a higher likelihood of behavioral problems (Heitzeg, 2016). 
When children can receive emotional support and cognitive stimulation in the home, disadvantages in verbal, reading, and math skills are significantly reduced (Jaffee \& Gallop, 2007; O’Malley, 2015).

\subsection{Parent and Child Relationship}

A common finding in resilience research is the power of a caring adult to tip the scale from risk to resilience for youth who are considered at-risk. Scott (2009) explored the maternal and family characteristics associated with academic success and resilience in African American families. The goal of the research study was to identify which family risk and protective factors most affected resilient children. Their findings suggest that the psychological disposition of the mother figure combined with parenting style is the most influential maternal characteristics that affect resilience in children of African descent. Results indicated that when there is an appropriate level of participation and interaction between the parent, the child tends to be more resilient and outcomes are generally more successful.

The research study of Simões and Alarcão (2014) found that mothers of resilient children reported lower levels of psychological distress, maternal risk attributes, and aggressive parenting styles than did the mothers of the non-resilient children. Their findings suggested that the psychological disposition of the mother figure combined with parenting style is the most influential maternal characteristics that affect resilience in children of African descent. Findings in the research literature indicate that when there is an appropriate level of participation and interaction between the parent and the child, outcomes are generally more successful. Munson (2010) posited that it is not feasible to define "good parenting" in any single description due to the variants of parent behavior across the developmental period of childhood or cultures defined by race, ethnicity, class, or geography. Thomas (2016) noted that there arecore parent behavioral and emotional strategies that appear to lead to relatively more successful child outcomes across time and culture. For example, it is well established that nurturing relationships afforded to children during infancy provides a foundation for healthy social development throughout childhood.

One major factor protecting children from the adverse effects of risk factors, according to Egeland (2004) is an excellent early foundation built on a secure relationship between parent and child. Jones (2012) asserts that resilience is not an innate trait in a child. Instead, resilience develops over time, and despite risk and adversity, parental support can bring about positive changes in the child. Kerpelman, Eryigit, and Stephens (2008) further suggested that parents must orient their children to the external environment, but African American parents have a special responsibility, given the hostile and restrictive environment in which their children live.

\subsection{Parental Involvement}

Parental involvement has been identified in many research studies (Greeff \& Fillis, 2009; Salazar, Harry, Hart, Klingner, 2005; Keller \& Courtney, 2011; Landau, 2007; Lewis, Butler, Bonner, \& Joubert, 2010)as a significant factor responsible for the academic success of at-risk populations. The academic achievement of vulnerable populations is often improved with parental involvement. When parents become involved, it reduces children's risk of academic failure and dropping out of school (Palmer, Davis, \& Hilton, 2009).

According to York, Gibson, \& Rankin (2015), one of the most significant predictors of child academic success is the level of involvement by the parent, which is based on (1) the educational level of a child's mother and (2) the socioeconomic level of the home. Their research found that parental involvement takes many forms including positive parenting practices in the home, providing a secure and stable environment, involvement in school activities, and having high expectations for the child. When all forms of parental involvement are studied, it is the 'at-home' relationships that play a significant role in school outcomes. Parental involvement indirectly impacts school outcomes by helping the child build self-esteem, higher educational outcomes (Jaffee, \& Gallop, 2007).

The relevant literature abounds with studies (Chaudry and Wimer, 2016; Edelman, 2016; Salazar et al., 2011;Schelble, Franks, \& Miller, 2010) showing significant differences between parents in their levels of involvement in their children's academic outcomes. Some of the differences are directly related to social class, poverty, and parent values. Some parents do not agree that they should be a partner in education (Price, 2015; Tillman, 2009). Others would like to participate, but do not think they can contribute to the academic process. Nevertheless, others are put off involvement by memories of their own school experience or by their interactions with their children's teachers or by a combination of both (Thomas, 2016). The studies of Delpit (2012); Hass \& Graydon (2009) and Price (2015) found that families of successful African American students had parents who were more involved in the educational process than those with lower levels of academic success. Their studies also showed that parental involvement differs at different socioeconomic levels.

Families with a higher level of parental education and family income demonstrated a higher level of parental involvement. Students that come from a family with low socioeconomic status demonstrated a lower level of parental involvement. 
Some of the most critical factors in parental involvement in their children's education are working conditions, cultural beliefs, gender differences, socioeconomic status, and household structures. When comparing African American parents to White parents Price (2015) found that the higher the education and income level of the parent, the higher the level of parental involvement. Price's findings are in contrast to an earlier study by Stevenson and Baker (1987), which suggest that there is no evidence to support the view of parental involvement and child's performance. However, the preponderance of research on parent involvement supports the idea that parental involvement is an essential factor for educational success and resilience.

\subsection{Implications for Practice}

The findings of this study have clear implications for educators as it reinforces the widely held belief that schools and parents must form strong coalitions to enhance student achievement. Parents who fail to maintain home environments conducive to learning need assistance and guidance as learning starts at home. Resilience studies consistently find that a positive learning environment at home has a powerful impact on student's achievement. Positive effects include significantly improved school behavior and improvement in general educational performance. Educators and local school districts can work with parents to ensure that they are aware of how positive parenting practices and a commitment to their child's education bring about changes that improve the child's chance for academic success. Allowing parents of academically successful children to serve as guest speakers at parenting classes, may provide the impetus that some parents need to become engaged in the education process.

The findings of this study also have clear implications for social work practitioners and policymakers who are involved with urban and inner-city issues. Social workers can be instrumental in identifying positive parenting practices that can be taught and modeled in training classes and interventions that help parents raise academically successful children. These training programs can be conducted in conjunction with local church outreach programs and efforts. Finally, the findings of this study can inform local housing officials and policymakers about the participant's belief that housing assistance programs should help get families out of at-risk neighborhoods.

Furthermore, family resilience studies make significant contributions to the academic success of students at risk. The main focus of this study was to add to the existing body of knowledge regarding factors that compel students from a socially and economically disadvantaged background to become resilient and to succeed academically despite the presence of adverse conditions.

The study of resilience has gained credence as a framework to investigate why students from similar demographic characteristics are successful in school, while others are not. The study findings of such a framework can inform the design of more effective educational interventions to empower at-risk students to be resilient and academically successful.

\subsection{Conclusions}

This study investigated factors and causes of resilience and academic success in African American youth based on the perceptions of the African American female single parent. Parents and other caregivers serve as the first line of defense against dysfunction in the lives of children. Changing developmental pathways for children and youth from risk to resilience starts in the home and is impacted by the attitudes and beliefs displayed in the family, school, and community.

The African American, female, single, parents in this study have shown that they can mitigate risk and provide protective factors for their children. The participants taught their children to believe that if they worked hard and applied themselves in school, they would be economically and socially rewarded. The goal of this research was achieved as it adds to the body of knowledge, which investigates the relationship of African American, female, single, parents and the overall academic achievement of African American youth.

This study is an essential addition to the scholarship of African American studies as it is a departure from the traditional deficits perspective of African American families. By viewing the African American single mother from a strength perspective, an alternative view is provided for anyone serious about understanding the African American women and more specifically black single motherhood. This work has important implications for improving resilience in African American children and in providing them with the chances for successful adulthood.

\section{References}

Allen, Q. (2015). 'I'm trying to get my A': Black male achievers talk about race, school and achievement. Urban Review, 47(1), 209-231. doi: 10.1007/s 11256-014-0315-4 
Archer-Banks, D. A., \& Behar-Horenstein, L. S. (2012). Ogbu Revisited: Unpacking High Achieving African American Girls High School Experiences. Urban Education,47(1), 198-223. doi:10.1177/0042085911427739

Arrington, E. G., \& Wilson, M. N. (2000). A re-examination of risk and resilience during adolescence: Incorporating culture and diversity. Journal of Child and Family Studies, 9(2), 221-230.

Brody, N. (2002). Construct validation of the Sternberg Triarchic Abilities Test (STAT): comment and reanalysis. Intelligence. 11 (1), 19-25.

Bryant, R. T., \& Center for Law and Social Policy, (. (2015). College Preparation for African American Students: Gaps in the High School Educational Experience.

Chaudry, A. and Wimer, C. (2016). Poverty is Not Just an Indicator: The Relationship Between Income, Poverty, and Child Well-Being. Academic Pediatrics, 16(3), pp.S23-S29.

Child Trends Databank. (2019). Children in poverty. Available at: https://www.childtrends.org/?indicators=children-inpoverty

Cokley, K., McClain, S., Jones, M., \& Johnson, S. (2011). A preliminary investigation of academic disidentification, racial identity, and academic achievement among African- American adolescents. High School Journal, 95(2), 54-68.

Crenshaw, K. (2012). Black Girls Matter: Pushed Out, Overpoliced And Underprotected. African American Policy Forum, 1 53. Retrieved September 9, 2016, from https://static1.squarespace.com/static/53f20d90e4b0b80451158d8c/t/54d2d37ce4b024b41443b0ba/1423102844010/ BlackGirlsMatterReport.pdf.

Cunningham, M., Corprew, C. I., \& Becker, J. E. (2009). Associations of Future Expectations, Negative Friends, and Academic Achievement in High-Achieving African American Adolescents. Urban Education, 44(3), 280-296

deCarvalho, J. N. \&Colvin, A. D. (2015). Emotional intelligence and academic success among low income college students. International Journal of Education and Social Science. 2(3)35-42

Delpit, L. D. (2012). Multiplication is for white people: raising expectations for other people's children. New York: New Press

Edelman, M. (2016). Ending Childhood Poverty in America. Academic Pediatrics, 16(3).

Edelman, M., \& Jones, J. (2004). Separate and unequal: America's children, race, and poverty: Journal of Child Development, $71(5), 1409-1423$.

Fox, L. (2018). The Supplemental Poverty Measure: 2017. Current Population Reports, Series P60-265, Table A-6. Retrieved fromhttps://www.census.gov/content/dam/Census/library/publications/2018/demo/p60- 265.pdf.

Gershenson, S., Holt, S. B., \& Papageorge, N. W. (2016). Who believes in me? The effect of student-teacher demographic match on teacher expectations. Economics of Education Review, 52, 209-224.

Giacobbe, G., Traynelis-Yerek, E., \& Laursen, E. (1999) Strengths based strategies for youth and children. Richmond: G \& T Publishing.

Gilliam, W., Maupin, A., \& Reyes, C. (2016). Do implicit biases regarding sex and race re-late to behavior expectation and recommendations of preschool expulsions and suspensions? New Haven, CT: Yale University Child Study Center.

Greeff, A. P., \& Fillis, A. J. (2009). Resiliency in poor single-parent families. Families in Society: The Journal of Contemporary Social Services, 90(3), 279-285.

Harry, B., Hart, J., Klingner, J. (2005). African American families under fire: Ethnographic $\quad$ views of family strengths. Remedial and Special Education. 26, (3) 35-43

Hass, M., \& Graydon, K. (2009). Sources of resiliency among successful foster youth. Children and Youth Services Review, $31(4), 457-463$.

Heitzeg, N. A. (2016). The school-to-prison pipeline: education, discipline and racialized double standards. Santa Barbara, CA: Praeger.

Hetherington, E., \& Stanley-Hagan, M. (2002). Parenting in divorced and remarried families. InM.H. Bornstein (Ed.), Handbook of parenting: Vol. 3. Being and becoming a parent (2nd ed., pp.233254). Mahwah, NJ: Lawrence Erlbaum Associates.

Hoffer, W. H. (2014). Plessy v. Ferguson: The effects of lawyering on a challenge to Jim Crow. Journal of Supreme Court History, 39(1), 1-21. doi:10.1111/j. 1540- 5818.2014.12037.x

Jaffee, S. R., \& Gallop, R. (2007). Social, emotional, and academic competence among children who have had contact with child protective services: Prevalence and stability estimates. Journal of the American Academy of Child \& Adolescent Psychiatry, 46(6), 757-765

Jones, L. (2012). Measuring resiliency and it predictors in recently discharged foster youth. Child Adolescent Social Work Journal, 29, 515-533. doi: 10.1007/s1056001200275

Kerpelman, J. L., Eryigit, S., \& Stephens, C. J. (2008). African-American adolescents' future education orientation: Associations with self-efficacy, ethnic identity, and perceived parental support. Journal of Youth Adolescence, 37(8), 997-1008.

Lacour, M. and L.D. Tissington (2011). The effects of poverty on academic achievement. Educational Research and Reviews, $1(1), 13-22$.

Landau, J. (2007). Enhancing resilience: Families and communities as agents of change. Family Process, 46(3), 351-365. 
Lewis, C. W., Butler, B. R., Bonner, F. A., \& Joubert, M. (2010). African-American male discipline patterns and school district responses resulting impact on academic achievement: Implications for urban educators and policy makers. Journal of African-American Males in Education, 1(1), 7-25

Lipsky, J., \& Johnson, K. (2010). Mentoring at-risk youth: Improving academic achievement in middle school students. Nonpartisan Education Review, 5(1), 235-242

Manago, A. M, Brown, C. S., \& Leaper, C. (2009). Feminist identity among latina adolescents. Journal of Adolescent Research, 24 (6), 750-776.

Mistry, R. S., Vandewater, E. A., Huston, A. C., \& McLoyd, V. C. (2002). Economic Well Being and Children's Social Adjustfemalest: The Role of Family Process in an Ethnically Diverse Low-Income Sample. Child Developfemalest, 73(3), 935.

Morris, M. (2016). Pushout: The Criminalization of Black Girls in Schools. New York, NY: $\quad$ The New Press

Munson, C.A. (2010). Leadership experiences of adolescent girls in a girl scouts after school program: a phenomenological approach (Dissertation). Retrieved from ProQuest Dissertations and Theses database.

National Center for Education Statistics (2016). Beginning postsecondary student longitudinal study. Washington, DC: U.S. Departfemalest of Education.

O’Malley, M. (2015), School climate, family structure, and academic achievement: A study of moderation effects. School Psychology Quarterly, 30(1): p. 142-157.

Palmer, R. T., Davis, R. J., \& Hilton, A. A. (2009). Exploring challenges that threaten to impede the academic success of academically underprepared black males at an HBCU. Journal of College Student Development, 50(4), 429-445.

Palmer, R. T., \& Maramba, D. C. (2011). African-American male achievement: Using a tenet of critical theory to explain the African-American male achievement disparity. Education and Urban Society, 43(4), 431-450. doi: 10.1177/0013124510380715

Price, V. (2015). The Quest for Success: A Phenomenological Study Aimed at Understanding the Experiences of Successful African American Females in High School. Educational Administration: Theses, Dissertations, and Student Research. Paper 249.

Richman, J., \& Fraser, M. (2001). The context of youth violence: Resilience: Risk and protection. Westport: Praeger

Salazar, A. M., Keller, T. E., \& Courtney, M. E. (2011). Understanding social support's role in the relationship between maltreatment and depression in youth with foster care experience. Child Maltreatment, 16(2), 102-113.

Schelble, J.L., Franks, B. A., \& Miller, M. D. (2010). Emotion dysregulation and academic resilience in maltreated children. In Child and Youth Care Forum (4th ed., Vol. 39, pp. 289-303). New York: Springer

Scott, W. R. (2009). Teachers' responsiveness to the learning needs of a select group of African American middle school students. (Unpublished doctoral dissertation). University of Florida, Gainesville.

Simões, F., \&Alarcão, M. (2014). Mentors and Teachers: Testing the effectiveness of simultaneous roles on school performance from a basic psychological need's satisfaction perspective. Instructional Science, 42(3), 465-483

Smith-Evans, L., \& George, J. (2014). Unlocking Opportunity for African American Girls. Women's National Law Center. Retrieved from: https://www.nwlc.org/sites/default/files/pdfs/unlocking_opportunity_for_african_american_girls_report.pdf

Snyder, D.T. \& S.A. Dillow (2015). Digest of educational statistics 2013 (NCES 2015-011)., Washington, DC: U.S. Department of Education, National Center for Education Statistics

Stinson, D. (2011). When the 'burden of acting white' is not a burden: School success and African-American male students. The Urban Review, 43(1), 43-65. doi:10.1007/s1 1256-009-0145-y

Stevenson, David L., and David P. Baker (1987). The family-school relation and the child's school performance. Child Development, 59, 1348-1357.

Tillman, L. C. (Ed.). (2009). The sage handbook of African American education. Thousand Oaks, CA: SAGE Publications

Swain, C. M. (2006). An Inside Look at Education and Poverty. Academic Questions, 19(2), 47 - 53.

Thomas, S. L. (2016). A phenomenological exploration of the experiences of students enrolled in school-wide college readiness programs (Order No. 3739342). Available from ProQuest Dissertations \& Theses A\&I; ProQuest Dissertations \& Theses Global. (1748613953). Retrieved from https://search.proquest.com/docview/1748613953?accountid=26417

York, T. T., Gibson, C., \& Rankin, S. (2015). Defining and measuring academic success. Practical Assessment Research \& Evaluation, 20(5), 1 -20.

Washington, B., (1901) Up from slavery: An autobiography. New York: A. L. BURT Company, Publishers 